\title{
COMPORTAMENTO PÓS-COLHEITA DE FRUTOS DE MORANGUEIRO APÓS A APLICAÇÃO PRÉ-COLHEITA DE QUITOSANA E ACIBENZOLAR-S- METIL ${ }^{1}$ \\ SERGIO MIGUEL MAZARO², CÍCERO DESCHAMPS ${ }^{3}$, LOUISE LARISSAMAY DE MIO³, LUIZANTÔNIO BIASI ${ }^{3}$, ALFREDO DE GOUVEA ${ }^{4}$, CLAUDIA KAEHLER SAUTTER ${ }^{5}$
}

RESUMO - O uso de indutores de resistência em plantas representa um método alternativo e promissor no controle de podridões póscolheita de frutos. Assim sendo, foi conduzido um experimento na Universidade Tecnológica Federal do Paraná - Câmpus Dois Vizinhos - PR, no ano de 2004, com objetivo de avaliar a aplicação pré-colheita de quitosana e acibenzolar-S-metil (ASM) sobre o comportamento pós-colheita de frutos de morangueiro da cultivar Aromas. O efeito da aplicação de quitosana $(0,5 ; 1,0$ e $2,0 \%)$ e de uma dose de ASM $(0,0025 \%)$ foi verificado em relação à testemunha (água destilada) e ao tratamento-controle com aplicação de fungicidas. A aplicação na pré-colheita de quitosana, nas três doses avaliadas, retardou a maturação dos frutos, manteve maior firmeza de polpa e acidez titulável e diminuiu a perda de massa. Esses tratamentos também diminuíram a produção de etileno, o teor de açúcares redutores e mantiveram mais elevado os teores de polifenóis totais. A aplicação de quitosana, nas três doses avaliadas, induziu maior resistência das plantas a patógenos, resultando na diminuição de podridão dos frutos em pós-colheita. No entanto, a concentração de $2 \%$ de quitosana causou dano aos frutos na pós-colheita, elevando a taxa respiratória e o teor de açúcares redutores. O ASM teve efeito na retenção da acidez titulável e na redução de podridões, similar ao tratamento com fungicidas. A aplicação de quitosana e ASM na pré-colheita não interferiu na qualidade organoléptica dos frutos em pós-colheita.

Termos para Indexação: elicitor, ASM, quitosana, morango, qualidade, Botrytis cinerea.

\section{POST HARVEST BEHAVIOR OF STRAWBERRY FRUITS AFTER PRE HARVEST TREATMENT WITH CHITOSAN AND ACIBENZOLAR-S-METHYL}

\begin{abstract}
The use of inductors of resistance in plants represents an alternative and a promising method to control fruit rots at post harvest. The experiment was carried out at Federal Technological University of Paraná - Dois Vizinhos - Campus, during 2004 with the objective to evaluate the induction of chitosan resistance and acibenzolar-S-methyl (ASM) on strawberry plants. The treatments compared the effect of chitosan $(0.5 ; 1.0$ and $2.0 \%)$ and $\operatorname{ASM}(0.0025 \%)$ in relation to control plants (distilled water only) and those with fungicides application. The chitosan treatment in all three evaluated concentrations, delayed the fruit maturation, increased the flesh firmness and titratable acidity and decreased the mass loss. It was also observed reduction in the ethylene production and in the reduced sugars and increased the total polyphenol in strawberry fruits. The chitosan treatment in all three evaluated concentrations induced greater plant resistance to diseases with effect on the reduction of the fruit rots in the post harvest by Botrytis cindered. Although, chitosan treatment in the concentration of $2 \%$ caused damage to the fruits in the post harvest increased the respiration rate and the reduced sugar. The ASM had effect on the retention of the titratable acidity and acted efficiently on the rot reduction similar to the treatment with fungicides. The application of chitosan and ASM pre-harvest did not interfere in the organoleptic quality of the fruits in the post harvest
\end{abstract}

Index Terms: elicitor, ASM, chitosan, strawberry, quality, Botrytis cinerea.

\section{INTRODUÇÃO}

O morango é um fruto de alta perecibilidade pós-colheita, característica natural da espécie, porém agravada por podridões, principalmente causadas por Botrytis cinerea Pers., Rhizopus stolonifer (Ehrenb.: Fr.) e Penicillium digitatum (Bautista-Baños et al., 2003). Essas perdas podem ser minimizadas através da redução dos danos mecânicos e manutenção dos frutos em condições adequadas de armazenamento na pós-colheita, como baixa temperatura, alta concentração de $\mathrm{CO}_{2}$ e atmosfera controlada (El Ghaouth et al., 1992). Atmosfera controlada, com altas concentrações de $\mathrm{CO}_{2}$, tem-se mostrado eficiente no retardo da maturação. Entretanto, concentrações excessivas podem causar danos aos frutos e perda de sabor quando excedem o limite tolerável (Li \& Kader, 1989), além de tal tecnologia ainda não ser acessível ao pequeno produtor. A aplicação em précolheita de fungicidas tem-se mostrado um método eficiente na redução de podridões na pós-colheita, principalmente pela redução da fonte de inóculo. No entanto, também o controle químico possui limitações como: alta contaminação com resíduos, encontrados em morangos, aumento da resistência dos patógenos

${ }^{1}$ (Trabalho 075-07). Recebido em: 23-03-2007. Aceito para publicação em: 20-07-2007.

${ }^{2}$ Eng $^{\circ}$ Agrônomo. Doutor, Professor, Universidade Tecnológica Federal do Paraná, Caixa postal 157, CEP 85.660-000 - Dois Vizinhos-PR. sergio@utfpr.edu.br

${ }^{3}$ Eng ${ }^{\circ}$ Agrônomo, Dr., Professor adjunto. Departamento de Fitotecnia e Fitossanitarismo da Universidade Federal do Paraná, Curitiba-PR. cícero@ufpr.br; biasi@ufpr.br,maydemio@ufpr.br

${ }^{4}$ Licenciado em ciências agrárias, Professor, Universidade Tecnológica Federal do Paraná, alfredo@utfpr.edu.br

${ }^{5}$ Professora, Dra. Núcleo de Pesquisa em Pós-colheita da Universidade Federal de Santa Maria. kaelher@terra.com.br 
e falta de fungicidas mais eficientes para a cultura do morangueiro (Paulus, 1990).

O uso de compostos naturais ou biodegradáveis, nãotóxicos, derivados de animais ou plantas, que apresentem efeito fungistático ou induzam a resistência natural das plantas, tem tomado destaque entre os fitopatologistas (Bautista-Baños et al., 2006). A quitosana é um polissacarídeo obtido da desacetilização da quitina, presente em invertebrados marinhos, insetos, fungos e leveduras (Mathur \& Narang, 1990), com efeito fungistático e indutor dos mecanismos de defesa das plantas (Terry \& Joyce, 2004). Quando aplicado em frutos de morango, tem demonstrado eficiência no controle de B. cinerea e R. stolonifer (El Ghaouth, 1992). A aplicação em pré-colheita de quitosana, além de controlar B. cinerea em pós-colheita mantém a firmeza de polpa e a acidez titulável, e seu uso em pós-colheita pode ser tão eficiente quanto o uso de fungicidas, induzindo enzimas de defesa e fitoalexinas e inibindo o crescimento de fungos (Reddy et al., 2000). A ação da quitosana está relacionada ao aumento da concentração endógena de ácido salicílico (Sathiyabama \& Balasubramanian, 1998), compostos fenólicos, indução de lignificação e síntese de fitoalexinas (Bautista-Baños et al., 2006), além da ativação das enzimas de defesa vegetal, como a quitinases e $\beta$-1,3-glucanases (Zhang \& Quantick, 1998).

O acibenzolar (ASM) é um elicitor sintético, com atuação na resistência sistêmica adquirida (Sticher et al., 1997), de forma análoga ao ácido salicílico (Vallad \& Goodman, 2004), acumula proteínas relacionadas à patogenicidade e fitoalexinas (Katz et al., 1998). Em morangos, a aplicação pré-colheita de ASM diminui a podridão pós-colheita causada por B. cinerea (Terry \& Joyce, 2000).

Sendo assim, este trabalho objetivou avaliar os efeitos da aplicação pré-colheita de quitosana e ASM sobre as principais características físicas-químicas, fisiológicas, bioquímicas e organolépticas, de interesse da tecnologia de pós-colheita, de frutos de morangueiro da cultivar Aromas.

\section{MATERIAL E MÉTODOS}

O trabalho foi conduzido em 2004, na Universidade Tecnológica Federal do Paraná, câmpus Dois Vizinhos - PR, onde foram realizadas as análises físicas-químicas (firmeza de polpa, sólidos solúveis totais, acidez titulável, perda de massa e podridões). As análises fisiológicas (respiração e produção de etileno) e bioquímicas (polifenóis, antocianinas e açúcares redutores) foram realizadas no Núcleo de Pesquisa em PósColheita da Universidade Federal de Santa Maria.

A cultivar de morango utilizada foi a Aromas, originária do Chile, cujo plantio foi realizado em maio de 2004, no espaçamento de $30 \times 30 \mathrm{~cm}$, com quatro fileiras por canteiro. $O$ sistema de plantio foi em túnel baixo, com fertirrigação, com duas fileiras de tubos gotejadores e com sistema de 'mulching ' plástico. O delineamento experimental foi o de blocos ao acaso, com 16 plantas por parcela e quatro repetições. Os tratamentos foram realizados nas plantas, com o uso de pulverizador manual, e incluíram 20 aplicações realizadas em intervalos de sete dias, sendo: quitosana nas concentrações de 0,$5 ; 1,0$ e 2,0\%, e ASM na dose de $0,0025 \%$; fungicidas recomendados para a cultura (tiofanato-metílico - 49g i.a./100L/água; iprodione - 75g i.a/100L/ água e folpete $-135 \mathrm{~g}$ i.a.100L/água) e a testemunha por aplicação de água destilada, na mesma forma e volumes dos demais tratamentos. A quitosana foi dissolvida em ácido acético a 1\%, e diluída com água para as concentrações utilizadas.

Os frutos de todas as parcelas foram colhidos e levados ao laboratório, pesados e selecionados. Os considerados fora do padrão de maturação, ou com ferimentos, foram desprezados. Em seguida, os frutos foram acondicionados em bandejas plásticas e mantidos sob temperatura média de $25^{\circ} \mathrm{C}$. As avaliações físicas-químicas foram realizadas em quatro repetições, cada qual composta por 25 frutos. A firmeza de polpa foi avaliada com uso de um penetrômetro manual de alta precisão, munido de uma ponteira de 7,9 $\mathrm{mm}$, perfurando-se cada fruta em dois lados opostos, na região equatorial. A acidez titulável foi determinada em uma amostra de $10 \mathrm{~mL}$ de suco dos frutos, extraído com auxílio de um multiprocessador, sendo essa amostra diluída para $100 \mathrm{~mL}$ de água destilada e titulada com uma solução de hidróxido de sódio $0,1 \mathrm{~N}$ até $\mathrm{pH} 8,1$. O teor de sólidos solúveis totais foi determinado por refratometria manual, e o resultado expresso em ${ }^{\circ}$ Brix. A perda de massa fresca foi obtida pela diferença de massa das amostras do dia da instalação do experimento e dos valores encontrados nas pesagens realizadas diariamente. Os frutos foram ainda avaliados segundo a presença ou não de injúrias, considerando como danificado o fruto que apresentasse características anormais de coloração. A avaliação da incidência de podridões foi realizada por análise visual e expressa em percentual de frutas. Para isso, foram consideradas frutas podres aquelas que apresentavam sintomas típicos (micélio aparente) de ataque de patógenos. Para melhor avaliação dos tratamentos sobre as podridões, foram realizadas quatro avaliações, no início e no final do ciclo da cultura, com inoculação a campo e em pós-colheita de Botrytis cinérea, conforme cronograma de datas apresentado na Tabela 1. A inoculação consistiu na pulverização da suspensão de conídios na concentração de $10^{5}$ esporos $/ \mathrm{mL}$ sobre as plantas e/ou frutos. Os inóculos foram preparados a partir de isolados de Botrytis cinerea obtidos de frutos do experimento a campo. As culturas puras foram desenvolvidas em placas de Petri, de $11 \mathrm{~cm} \mathrm{de}$ diâmetro, contendo meio de BDA (batata $200 \mathrm{~g}$, dextrose $20 \mathrm{~g}$, ágar $20 \mathrm{~g}$ e água destilada $1.000 \mathrm{~mL}$ ), mantidas em estufa incubadora tipo $\mathrm{BOD}, \mathrm{a} 23^{\circ} \mathrm{C}$, e fotoperíodo de 12 horas. Nessas placas, foram adicionados $10 \mathrm{~mL}$ de água destilada e então procedeu-se à raspagem da superfície das colônias com uma lâmina de microscopia esterilizada. Em seguida, a suspensão de inóculo obtida foi filtrada, determinando-se a concentração de esporos com a câmara de Neubauer.

Para a determinação da produção de etileno, 25 frutos de cada tratamento, em quatro repetições, foram acondicionados em recipientes de vidro de $5 \mathrm{~L}$ de capacidade, hermeticamente fechados, durante duas horas a $20^{\circ} \mathrm{C}$. Após esse período, duplicatas de $1 \mathrm{~mL}$ da atmosfera interior dos recipientes foram injetadas em cromatógrafo a gás, marca Varian ${ }^{\circledR}$, modelo 3400. Por meio da concentração de etileno, da massa dos frutos, do volume do espaço livre no recipiente e do tempo, foi calculada a 
produção de etileno para ser expressa em $\mathrm{mL} \cdot \mathrm{kg}^{-1} \cdot \mathrm{h}^{-1}$.

A respiração foi avaliada pela produção de $\mathrm{CO}_{2}$ dos frutos. Para isso, $\mathrm{o}$ ar do mesmo recipiente utilizado para a determinação anterior foi circulado através de um analisador eletrônico de $\mathrm{CO}_{2}$, marca Agri-Datalog ${ }^{\circledR}$ Por meio da concentração de $\mathrm{CO}_{2}$, do volume do espaço livre, da massa dos frutos e do tempo de fechamento, foi calculada a respiração em $\mathrm{mL} \cdot \mathrm{CO}_{2} \cdot \mathrm{kg}^{-1} \cdot \mathrm{h}^{-1}$.

O total de açúcares redutores foi determinado pelo método titulométrico de Lane \& Eynon (1934), e a de polifenóis, pelo método colorimétrico descrito em Singleton \& Rossi (1965). A determinação de antocianinas totais obedeceu aos critérios descritos por Di Stefano et al. (1989).

A avaliação sensorial foi realizada por um grupo de dez degustadores não-treinados, adotando-se dois níveis de qualidade: nível 1 com sabor, aroma ou textura anormal, e nível 2 com todos esses parâmetros aceitos como normais.

Os resultados obtidos foram submetidos à análise de variância e a comparação de médias pelo teste de Tukey, a 5\% de probabilidade. Valores percentuais foram transformados em arcoseno. $\sqrt{x / 100}$, para análise da variância.

\section{RESULTADOS E DISCUSSÃO}

A aplicação de quitosana, independentemente da concentração, diminuiu a dinâmica de maturação, atenuando as perdas de firmeza de polpa e acidez titulável, quando comparada com os demais tratamentos (Figura 1A e 1C). O ASM manteve mais elevada a acidez titulável quando comparado à testemunha, com efeito semelhante ao tratamento com quitosana (Figura 1C). $\mathrm{O}$ efeito de quitosana sobre a retenção de firmeza e a acidez titulável foram observados por Reddy et al. (2000), sendo que a manutenção da firmeza foi relacionada com o incremento nas concentrações de quitosana. A manutenção da acidez titulável em frutos de morangos tratados com quitosana já tinha sido observada por Han et al. (2004). A perda da acidez está relacionada ao processo natural de maturação dos frutos, pois ocorre utilização dos ácidos orgânicos, principalmente cítrico e málico em morangos, como substrato no processo respiratório via ciclo de Krebs. A perda de massa fresca após o terceiro dia de avaliação também foi menor com o uso de quitosana (Figura 1D), fato esse já observado anteriormente em morangos por Han et al. (2004). Os teores de sólidos solúveis totais (SST) não sofreram alteração em função dos tratamentos e mantiveram-se dentro da normalidade na vida pós-colheita dos morangos (Figura 1B).

Em todas as avaliações realizadas de incidência de podridões, os patógenos observados foram $B$. cinerea, $R$. stolonifer e $P$. digitatum, sendo acima de $95 \%$ das infecções causadas por $B$. cinerea, fato esse explicável devido ao processo de inoculação no campo e em pós-colheita desse patógeno. $\mathrm{O}$ uso de quitosana, nas três concentrações avaliadas, induziu a planta à maior resistência a patógenos, apresentando efeito na diminuição das podridões de frutos em pós-colheita em relação à testemunha (Tabela 1).

No entanto, na concentração de $2 \%$ de quitosana ocorreu dano aos frutos em pós-colheita, desenvolvendo uma coloração anormal nos mesmos, atingindo uma incidência de 22,5 e $27,5 \%$ de frutos com danos, na primeira e segunda avaliações, respectivamente. Esse dano não alterou as características organolépticas nos frutos, mas depreciou-os para o mercado, apresentando uma coloração atípica em comparação aos demais tratamentos, com mais brilho e coloração vermelhopúrpura, diferente dos demais, com coloração vermelho-intensa. O efeito da aplicação de quitosana sobre podridões em morango na pós-colheita, causado por B. cinerea e R. stolonifer, foi relatado por El Ghaouth et al. (1992), demonstrando também seu efeito in vitro na inibição da germinação de esporos, na elongação do tubo germinativo e no crescimento da colônia. O efeito de quitosana sobre $B$. cinerea está relacionado com a concentração do produto, sendo que a incidência de podridões diminuiu com o aumento da dose de quitosana e aumentou com o período de armazenamento e a elevação da temperatura (Reddy et al., 2000). $\mathrm{O}$ efeito de quitosana sobre podridões está relacionado à preservação da integridade da membrana e redução da produção de poligalacturonase por $B$. cinerea, bem como no dano direto à citologia da hifa, limitando a habilidade do patógeno de colonizar o tecido (El Ghaouth et al., 1997). O controle de podridões de morango observado neste trabalho também pode ser atribuído à propriedade fungistática de quitosana, efeito "coast", habilidade de induzir a resistência sistêmica adquirida, com produção de compostos de defesa, como polifenóis, ou mais provável a combinação desses fatores.

O ASM atuou de forma eficiente na redução de podridões, com resultados similares aos do tratamento com fungicidas e destacando-se em relação à testemunha (Tabela 1). O efeito de ASM em morangueiros já foi observado para o controle de B. cinerea (Terry \& Joyce, 2000) e P. fragariae (Eikemo et al., 2003). O ASM, possivelmente, atuou na ativação da resistência sistêmica adquirida, conforme descrito por Sticher et al. (1997), expressando as proteínas relacionadas à patogenicidade (Katz et al., 1998), as quais atuam diretamente contra as paredes celulares de fungos, hidrolisando os polímeros de quitina e glucana, enfraquecendo a parede celular e tornando as células osmoticamente sensíveis.

A avaliação de podridões sem e com inoculação a campo e sem e com inoculação em pós-colheita, e realizada no início e no final do ciclo produtivo, permitiu avaliar o efeito da pressão de inóculo sobre a incidência de podridões após os tratamentos. Tanto que a primeira avaliação, no início do ciclo produtivo, foi realizada 7 dias após a colheita, e a segunda, no final do ciclo produtivo, com apenas 4 dias, pois a incidência de podridões já atingia níveis acima de $50 \%$ de frutos podres na testemunha (Tabela 1). Essa redução do tempo de avaliação, de 7 dias para 4 dias, demonstra o efeito da pressão do inóculo sobre a incidência de podridões.

Nos tratamentos com quitosana nas concentrações de $0,5 \%$ e $1,0 \%$, foi observada uma redução na respiração dos frutos (Tabela 2). A redução na taxa respiratória e da atividade de polifenol oxidase pelo uso de quitosana também foi observada em frutos de longan (Jiang \& Li, 2001). No presente trabalho, na concentração de $2 \%$, ocorreu uma elevação da taxa respiratória em comparação com as doses de 0,5 e $1 \%$ (Tabela 2). 
Possivelmente, isso se deve ao fato de os frutos, nessa concentração, terem apresentado danos. Danos em frutos resultam no aumento do metabolismo, que se torna aparente com o aumento da taxa respiratória (Varoquaux \& Wiley, 1997, citado por Moraes, 2005).

A produção de etileno foi menor nos tratamentos com quitosana, nas três concentrações avaliadas, em comparação com a testemunha, sendo que a $0,5 \%$ não diferiu do tratamento com ASM e fungicidas (Tabela 2).

Quitosana, nas três concentrações avaliadas, manteve mais elevado os valores de polifenóis totais em comparação com a testemunha (Tabela 2). A manutenção nos fenóis totais pelo uso de quitosana também foi observado em frutos de lichia (Zhang \& Quantick, 1997). Os tratamentos com quitosana, na dose de 0,5 e 1,0\%, e ASM resultaram em menores valores de açúcares redutores em comparação com a testemunha, sendo que, na concentração de $2 \%$, observou-se elevação do teor de açúcares redutores (Tabela 2). Possivelmente, essa elevação dos açúcares redutores está relacionada ao dano verificado nos frutos tratados com 2,0\% de quitosana. Esse dano pode ter desencadeado um aumento da atividade metabólica dos frutos, elevando os níveis de açúcares redutores e aumentando a sua respiração. El Ghaouth et al. (1991) associaram o aumento da respiração em morangos com podridões pós-colheita.

Com relação ao teor de antocianinas, ocorreu um discreto aumento delas na testemunha, em comparação com os demais tratamentos, porém sem diferenças estatísticas (Tabela 2). Isto pode estar relacionado ao seu aumento pelo processo natural de maturação dos frutos, conforme observado por Reddy et al. (2000).

A aplicação de quitosana e de ASM na pré-colheita não interferiu na qualidade organoléptica dos frutos na pós-colheita, não sendo observado sabor estranho nos frutos pelo grupo de degustadores.
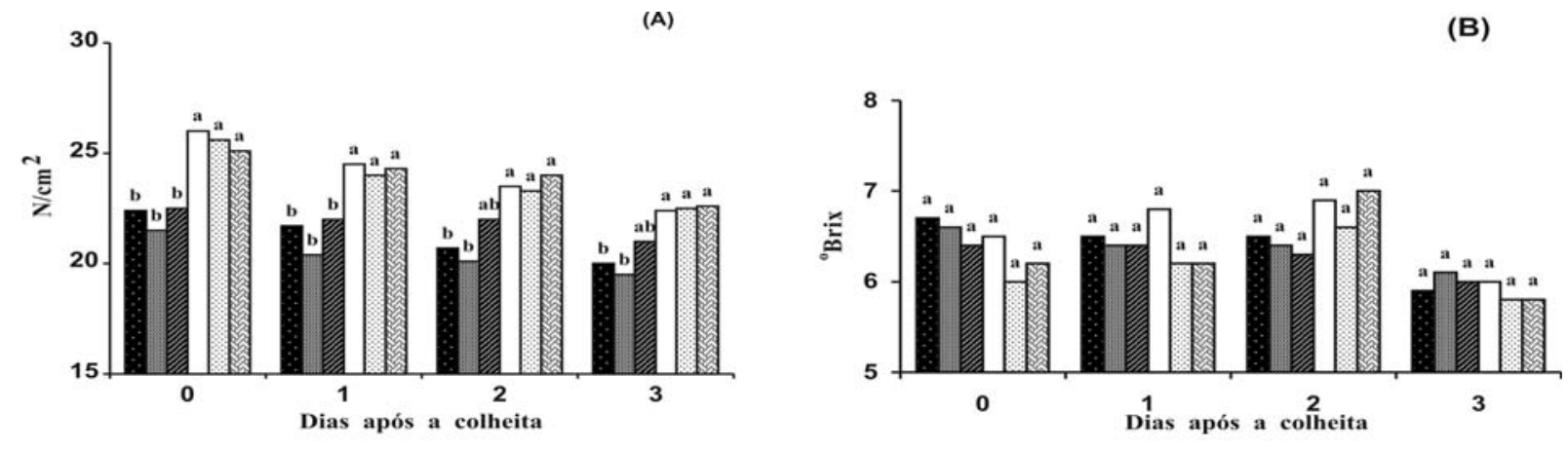

(C)
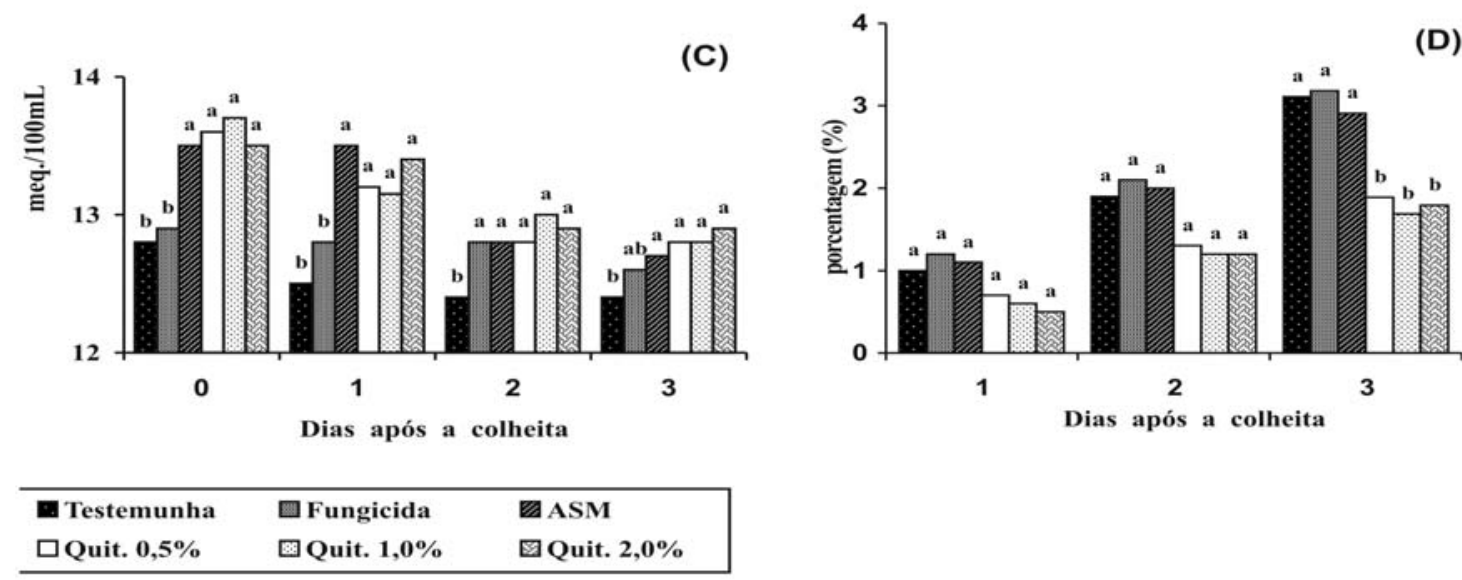

FIGURA 1 - Comportamento da firmeza de polpa (A), sólidos solúveis totais (B), acidez titulável (C) e perda de massa (D) de frutos de morangueiro da cultivar Aromas não-tratados e tratados na pré-colheita com elicitores e fungicidas. Dois Vizinhos-PR, 2004.

Rev. Bras. Frutic., Jaboticabal - SP, v. 30, n. 1, p. 185-190, Março 2008 
TABELA 1- Incidência de podridões pós-colheita (\%) de frutos de morangueiro da cultivar Aromas, não-tratados e tratados em pré-colheita com elicitores e fungicidas. Dois Vizinhos-PR, 2004.

\begin{tabular}{|c|c|c|c|c|}
\hline \multirow{4}{*}{ Tratamentos } & \multicolumn{4}{|c|}{$\%$ podridões fúngicas } \\
\hline & \multirow{3}{*}{$\begin{array}{c}\text { Sem } \\
\text { inoculação no } \\
\text { campo**(1) }\end{array}$} & \multicolumn{3}{|c|}{ Com inoculação no campo } \\
\hline & & \multicolumn{2}{|c|}{ Sem inoculação em pós-colheita } & \multirow{2}{*}{$\begin{array}{l}\text { Com inoculação em } \\
\text { pós-colheita } \\
\text { Final do ciclo*** (4) }\end{array}$} \\
\hline & & Início do ciclo** (2) & Final do ciclo ${ }^{* * *(3)}$ & \\
\hline Testemunha & $18,7 \mathrm{a} *$ & $32,5 \mathrm{a}$ & $42,5 \mathrm{a}$ & $57,5 \mathrm{a}$ \\
\hline Fungicidas & $12,5 b$ & $15,0 \mathrm{~b}$ & $17,5 b$ & $32,5 \mathrm{bc}$ \\
\hline ASM & $12,5 \mathrm{~b}$ & $16,6 \mathrm{~b}$ & $17,5 b$ & $35,0 \mathrm{~b}$ \\
\hline Quitosana $0,5 \%$ & $10,0 \mathrm{~b}$ & $13,3 \mathrm{bc}$ & $22,5 b$ & $30,0 \mathrm{bc}$ \\
\hline Quitosana 1\% & $6,25 \mathrm{c}$ & $10,0 \mathrm{c}$ & $17,0 \mathrm{~b}$ & $27,5 \mathrm{c}$ \\
\hline Quitosana 2\% & $6,75 \mathrm{c}$ & $10,0 \mathrm{c}$ & $25,0 \mathrm{~b}$ & $37,5 b$ \\
\hline C.V. & 8,6 & 11,5 & 23,7 & 14,5 \\
\hline
\end{tabular}

* Médias seguidas pela mesma letra na coluna não diferem, pelo teste de Tukey, a $5 \%$ de probabilidade de erro.

** Avaliação após 7 dias da colheita.

*** Avaliação após 4 dias da colheita.

(1) $1^{\circ}$ Avaliação de podridões em pós-colheita de frutos sem a inoculação a campo, realizada em 31 de julho de 2004 .

(2) $2^{\circ}$ Avaliação de podridões em pós-colheita de frutos com inoculação a campo e sem inoculação em pós-colheita, no início do ciclo produtivo da planta, realizada em 22 de agosto de 2004

(3) $3^{\circ}$ Avaliação de podridões em pós-colheita de frutos com inoculação a campo e sem inoculação em pós-colheita, no final do ciclo produtivo da planta, realizada em $1^{\circ}$ de novembro de 2004

(4) $4^{\circ}$ Avaliação de podridões em pós-colheita de frutos com inoculação a campo e com inoculação em pós-colheita, no final do ciclo produtivo da planta, realizada em 09 de novembro de 2004.

TABELA 2 - Respiração, produção de etileno, teores de polifenóis totais, de antocianinas totais e de açúcares redutores de frutos de morangueiro da cultivar Aromas não-tratados e tratados na précolheita com elicitores e fungicidas. Dois VizinhosPR, 2004.

\begin{tabular}{|c|c|c|c|c|c|}
\hline Tratamentos & $\begin{array}{l}\text { Respiração } \\
\left(\mathrm{mLCO}_{2} \mathrm{~kg}^{-1}\right)\end{array}$ & $\begin{array}{l}\text { Produção de } \\
\text { etileno } \\
\text { ( } \mathrm{uLC}_{2} \mathrm{H}_{4} \cdot \mathrm{kg}^{-1} \text { ) }\end{array}$ & $\begin{array}{l}\text { Polifenóis totais } \\
\text { (mg ácido gálico- } \mathrm{L}^{-1} \text { ) }\end{array}$ & $\begin{array}{l}\text { Antocianinas } \\
\text { (mg. } \mathrm{L}^{-1} \text { cloreto de } \\
\text { malvidina) }\end{array}$ & $\begin{array}{l}\text { Açúcares } \\
\text { redutores } \\
\text { (g de açúcar } \\
\text { redutor. } 100 \mathrm{~mL}^{-1} \text { ) }\end{array}$ \\
\hline Testemunha & 47,91a & $0,308 \mathrm{a}$ & $112,5 \mathrm{c}$ & $0,38 \mathrm{~ns}$ & $7,5 \mathrm{a}$ \\
\hline Fungicidas & $46,26 \mathrm{~b}$ & $0,281 \mathrm{ab}$ & $114,6 b c$ & 0,32 & $3,1 b c$ \\
\hline ASM & $47,46 \mathrm{a}$ & $0,276 \mathrm{ab}$ & $114,4 b c$ & 0,29 & $1,6 \mathrm{c}$ \\
\hline Quitisana 0,5\% & $41,06 \mathrm{c}$ & $0,245 b$ & $120,7 \mathrm{a}$ & 0,36 & $1,6 \mathrm{c}$ \\
\hline Quitosana 1,0\% & $42,32 \mathrm{c}$ & $0,202 \mathrm{c}$ & $116,1 a b$ & 0,34 & $1,5 \mathrm{c}$ \\
\hline Quitosana 2,0\% & $44,06 \mathrm{~b}$ & $0,159 \mathrm{c}$ & $117,8 \mathrm{ab}$ & 0,35 & $4,2 b$ \\
\hline C.V. & 6,64 & 16,4 & 12,40 & 10,98 & 6,5 \\
\hline
\end{tabular}

* Médias seguidas pela mesma letra na coluna não diferem, pelo teste de Tukey, a $5 \%$ de probabilidade de erro.

\section{CONCLUSÕES}

1- A aplicação pré-colheita de quitosana, nas doses de $0,5 \% ; 1,0 \%$ e $2,0 \%$, retarda a maturação dos frutos por atuar positivamente na manutenção da firmeza de polpa, acidez titulável e aumentar os teores de polifenóis totais, além de diminuir a produção de etileno, a perda de massa fresca e o teor de açúcares redutores.

2- A quitosana induz na planta a resistência a patógenos, com efeito na diminuição das podridões de frutos na pós-colheita, sendo que a concentração de $2 \%$ causa dano aos frutos na póscolheita.

3- O ASM tem efeito na retenção da acidez titulável e atua na redução de podridões.

4- A aplicação de quitosana e de ASM na pré-colheita não interfe na qualidade organoléptica dos frutos em póscolheita.

\section{REFERÊNCIAS}

BAUTISTA-BAÑOS, S.; GARCÍA-DOMINGUEZ, E.; BARRERANECHA, L.L.; REYES-CHILPA, R.; WILSON C.L. Seasonal evalution of postharvest fungicidal activity of powders and extracts of huamuchil (Pithecellobium dulce): action against Botrytis cinerea, Penicillium digitatum and Rhyzopus stolonifer of strawberry fruit. Postharvest Biology and Technology, Amsterdan, v.29, p.81-93, 2003.

BAUTISTA-BAÑOS, S.; HERNÁNDEZ-LAUZARDO, A.N.; VALLE, M.G.V.; HERNÁNDEZ-LÓPEZ, M.; BARKA, E.A.; BOSQUEZ-MOLINA, E.; WILSON C.L. Chitosan as a potential natural compound to control pre and postharvest diseases of horticultural commodities. Crop Protection, London, v.25, p.108118, 2006.

DI-STEFANO, R.; CRAVERO, M.C.; GENTILINI, N. Metodi per lo studio dei polifenoli dei vini. L'Enotecnico, p.83-89, 1989.

EIKEMO, H. ; STENSVAND A. ; TRONSMO, A.M. Induced resistance as a possible means to control diseases of strawberry caused by Phytophthora spp. Plant Disease, St. Paul, v.87, n.4, p.345-350, 2003.

EL GHAOUTH, A.; ARUL, J.; WILSON, C.; BENHAMOU, N., Biochemical and cytochemical aspects of the interactions of chitosan and Botrytis cinerea in bell pepper fruit. Postharvest Biology and Technology, Amsterdan, v.12, 183-194, 1997.

EL GHAOUTH, A.; ARUAL, J.; GRENIER, J.; ASSELIN, A. Antifungal activity of chitosan on two postharvest pathogens of strawberry fruits. Phytopathology, S. Paul, v.82, p.398-402, 1992.

EL GHAOUTH, A.; ARUAL, J.; PONNAMAPALAM, R.; BOULET, M. Chitosan coating effect on storability and quality of fresh strawberries. Journal of Food Science, Chicago, v.56, p.1618-1620, 1991. 
HAN, C.; ZHAO, Y.; LEONARD, S.W.; TRABER, M.G. Edible coatings to improve storability and enhance nutritional value of fresh and frozen strawberries (Fragaria $x$ ananassa) and raspberries (Rubus ideaus). Postharvest Biology and Technology, Amsterdan, v.33, p.67-78, 2004.

JIANG, Y.; LI, Y., Effects of chitosan coating on postharvest life and quality of longan fruit. Food Chemistry, Oxford, v.73, 139143,2001

KATZ, V.A.; THULKE, O.U.; CONRATH, U. A benzothiadiazole primes parsley cells for augmented elicitation of defense responses. Plant Physiology, Washington, v.117, 1333-1339, 1998.

LANE, J. H.; EYNON, L. Determination of reducing sugars by Fehling's solution with methylene blue indicator. Normam Rodge, London, 8p., 1934.

LI, C.; KADER, A.A. Residual effect of controlled atmospheres on postharvest physiology and quality of strawberries. Journal of American Society for Horticultural Science, Alexandria, v.114, p.629-634, 1989.

MATHUR, N. K.; NARANG, C.K. Chitin and Chitosan, Versatile Polysaccharides from Marine Animals. Journal of Chemical Education, Madison, v.67, n.11, p.938-942, 1990.

MORAES, I.V.M. Morango processado minimamente e conservado sob refrigeração e atmosfera controlada. Campinas, 2005. 98p. Dissertação de mestrado. Faculdade de Engenharia Agrícola, Universidade Estadual de Campinas.

PAULUS, A.O. Fungal diseases of strawberry. HortScience, Alexandria, v.25, p.885-889, 1990.

REDDY, M.V.B.; BELKACEMI, K; CORCUFF, R. CASTAIGNE, F. ARUL, J. Effect of pre-harvest chitosan sprays on post-harvest infection by Botrytis cinerea and quality of strawberry fruit. Postharvest Biology and Technology, Amsterdan, v.20, p.39-51, 2000.
SATHIYABAMA, M.; BALASUBRAMANIAN, R. Chitosan induces resistance components in Arachis hypogaea against leaf rust caused by Puccinia arachidis Speg. Crop Protection, London,v.17, p.307-313, 1998.

SINGLETON, V.L.; ROSSI, J.A. Colorimetric of total phenols with phosphoromolybdic-phosphotugstic acid reagents. American Journal of Enology and Viticulture, Davis, v.20, n.3, p.144-158, 1965.

STICHER, L.; MAUCH-MANI, B.; MÉTRAUX, J.P. Systemic acquired resistance. Annual Review Phytopathology, Palo Alto, v.35, p.235-270, 1997.

TERRY, L.A.; JOYCE, D.C., Suppression of grey mould on strawberry fruit with the chemical plant activator acibenzolar. Pest Management Science, Hoboken, v.56, p.989-992, 2000.

TERRY, L.A.; JOYCE, D.C. Elicitors of induced disease resistance in posharvest horticultural crops: a brief review, Postharvest Biology and Technology, Amsterdan, v.32, p.1-13, 2004.

VALLAD, G.E.; GOODMAN, R.M. Systemic Acquired Resistance and Induced Systemic Resistance in Conventional Agriculture, Crop Science Society of America, Madison, v.44, p.1920-1934, 2004.

ZHANG, D.; QUANTICK, P.C. Antifungal effects of chitosan coating on fresh strawberries and raspberries during storage. Journal of Horticultural Science \& Biotechnology, Ashford, v.73, p.763-767, 1998 .

ZHANG, D.; QUANTICK, P.C. Effects of chitosan coating on enzymatic browning and decay during postharvest storage of litchi (Litchi sinensis Sonn.) fruit. Postharvest Biology and Technology, Amsterdan, v.12, p.195-202, 1997. 